\title{
Inclusão digital no Instituto Federal de Educação, Ciência e Tecnologia - Campus Venâncio Aires
}

\author{
Marlon Mendes Minussi' ${ }^{1}$, Fábio Luís da Silva Santos ${ }^{2}$ \\ ${ }^{1}$ Instituto Federal de Educação, Ciência e Tecnologia Sul-rio-grandense - Campus \\ Venâncio Aires, Avenida das Indústrias, 1865 - Bairro Universitário - CEP 95.800-000 \\ - Venâncio Aires, RS - Brasil \\ ${ }^{2}$ Instituto Federal de Educação, Ciência e Tecnologia Sul-rio-grandense - Campus \\ Charqueadas, Charqueadas, RS - Brasil \\ marlonminussi@ifsul.edu.br, fabio3268@gmail.com
}

\begin{abstract}
This paper aims to present the profile and features of the participants as well as discover their motivation to search for the Digital Inclusion course developed by IFSUL - Venancio Aires. The extension project exists since June 2012, e for the good search, it became necessary to do profiling of the students. It is a qualitative search and as methodology it was used a questionnaire with open and closed questions. One of the aspects highlighted on the research is that the search for the course started because of the need for adequacy for the job market.
\end{abstract}

Resumo. Este artigo visa apresentar o perfil e as características dos participantes, bem como, conhecer sua motivação para procura do curso de inclusão digital desenvolvido no IFSUL-Venâncio Aires. O projeto de extensão existe desde junho de 2012, e pela grande procura sentiu-se a necessidade de traçar o perfil dos alunos. Trata-se de uma pesquisa qualitativa e como metodologia foi utilizada um questionário com perguntas abertas e fechadas. Um dos aspectos destacados na pesquisa é que a procura pelo curso surgiu pela necessidade de atualização e adequação para o mercado de trabalho.

\section{Introdução}

No país os recursos tecnológicos crescem a passos largos. Cada vez mais as pessoas convivem com estes recursos no seu dia-a-dia. O computador, seja ele uma ferramenta de trabalho, instrumento de entretenimento ou em serviços, se tornou um item indispensável às pessoas.

Tendo em vista este cenário, muito se fala da inclusão digital, que nada mais é do que um processo de popularização do acesso às tecnologias da informação. A inclusão digital não é apenas a apresentação do computador às pessoas, e sim, fornecer o conhecimento e fazer com que este sirva para a mudança de seu quadro social.

Para Mello e Teixeira (2007), na sociedade marcada pela presença das tecnologias, o acesso à internet torna-se elemento fundamental de inclusão social. Entretanto, é necessário que se reconheça que, em razão das grandes desigualdades sociais do Brasil, um número extremamente reduzido de indivíduos possui acesso domiciliar a esses recursos, sendo a escola o principal, senão o único, espaço de contato com tais meios. É preciso que se reconheça que a falta de acesso à informação referente 
à utilização de recursos tecnológicos na educação e a pouca infraestrutura disponível nos ambientes educacionais brasileiros são alguns dos fatores que colaboram para a negação desses espaços pelos professores e para a manutenção de situações de exclusão digital dos alunos.

No Brasil, hoje muitas instituições estão praticando ações referentes à inclusão digital. Existem projetos nas diversas modalidades. Porém, ainda, muitas ações são limitadas devido à falta de recursos.

Para Santos (2009) as escolas são componentes essenciais à inclusão digital uma vez que professores, alunos, especialistas e membros da comunidade podem se reunir e atuar em prol do processo de construção de conhecimento.

Motivado a isso, no ano de 2012, iniciou-se um projeto de extensão de inclusão digital, no Instituto Federal de Educação, Ciência e Tecnologia Sul-rio-grandense IFSUL - Campus Venâncio Aires, executado por Professores e alunos do Curso Técnico de Informática, sendo este, disponibilizado para a população do município de Venâncio Aires. Considerando que a escola precisa ser um espaço de convivência entre as pessoas da comunidade, abrindo seu leque de atuação, o projeto de extensão em inclusão digital realizado no IFSUL justifica-se pela necessidade de incluir pessoas, utilizando as tecnologias de informação e comunicação como instrumento de construção e exercício da cidadania.

O projeto é oferecido a toda população do Município de Venâncio Aires e Região, as quais são selecionadas de acordo com seu perfil socioeconômico. Atualmente tem dois instrutores, sendo um aluno bolsista e outro voluntário, conta com 04 turmas, atendendo um total de 60 alunos. As aulas são realizadas no IFSUL e em uma Escola do Município. O curso tem um total de 40 horas, sendo realizada uma aula na semana, com duração de duas horas. $\mathrm{O}$ conteúdo consiste em aulas práticas quanto ao uso do sistema operacional, internet e ferramentas de desenvolvimento pessoal.

Esta pesquisa tem como objetivos, identificar o perfil e as características dos participantes, bem como, conhecer sua motivação para procura do curso de inclusão digital desenvolvido no IFSUL-Venâncio Aires.

\section{Material e métodos}

Este trabalho foi desenvolvido no Instituto Federal de Educação, Ciência e Tecnologia Sul-rio-grandense (IFSUL), na Cidade de Venâncio Aires, localizada na Região Central do Estado do Rio Grande do Sul, sendo este, fundado no ano 2011. O IFSUL atende atualmente 600 alunos, oferecendo cursos técnicos integrados e subsequentes.

A presente pesquisa teve como público alvo os alunos curso de inclusão digital que estão ligados ao projeto de extensão em inclusão digital.

Como instrumentos de coleta de dados foi adotado um questionário com perguntas abertas e fechadas, sendo este criado para atender os objetivos propostos.

\section{Apresentação dos resultados}

Após aplicação dos questionários os dados foram codificados e apresentados em forma descritiva e em gráficos.

Pode-se verificar a faixa etária dos participantes do projeto, sendo 13\% entre 31 
e 40 anos, $39 \%$ entre 41 à 50 anos e $48 \%$ dos participantes com mais de 50 anos. Podese verificar que a maioria dos participantes tem mais de 40 anos. Destes é predominante o interesse da mulher ao acesso às tecnologias, com 58\% dos participantes do sexo feminino contra $42 \%$ do masculino.

Quanto ao nível de escolaridade dos participantes (Figura 1), percebemos que a maioria não possui ensino fundamental completo, sendo $42 \%$ nesta categoria, o restante mostra que $19 \%$ tem o ensino fundamental incompleto, $19 \%$ ensino médio incompleto, $13 \%$ com ensino médio completo e apenas $7 \%$ com nível superior.

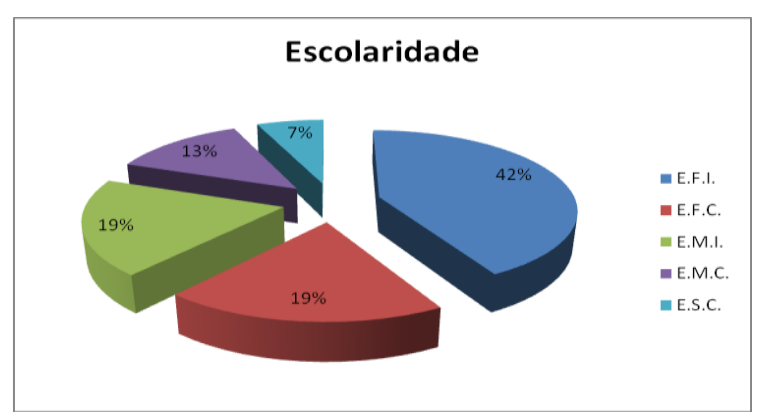

Figura 1. Escolaridade

Em relação as preferências dos participantes, quanto à utilização do computador, o uso para acesso à internet prevalece nas respostas, sendo este item a preferência de $74 \%$ dos participantes, os demais utilizam para jogos, sendo $7 \%$ e $19 \%$ utilizam com outros fins.

A figura 2 apresenta dados quanto à forma de acesso ao computador, sendo predominante os que possuem acesso ao computador em casa, nesta categoria estão $77 \%$ dos participantes, ficando acima da média, da região sul do Brasil, que segundo dados do Centro de Estudos sobre as Tecnologias da Informação e da Comunicação (CETIC.br) é de 55\% de pessoas com computador em casa. Os demais participantes possuem acesso ao computador escolas, sendo $16 \%$ e no trabalho sendo estes $7 \%$ dos participantes.

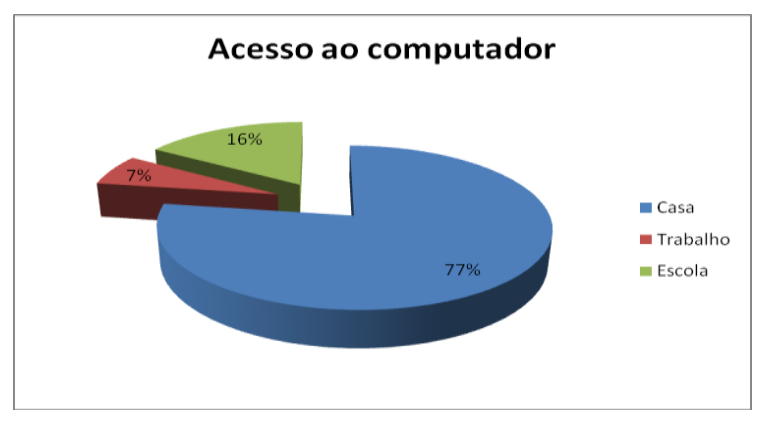

Figura 2. Acesso ao Computador

Quanto ao acesso à internet (Figura 3) 65\% dos participantes possui acesso à internet no domicílio, este dado quando cruzado com as pessoas que possuem computador em casa, demonstra que nem todas as pessoas que possuem o computador possuem acesso à internet. Este dado é superior ao apresentado pela pesquisa IBGE do ano de 2011, onde apenas 39,4\% da população do País, possuem acesso à internet no domicílio. Os demais possuem acesso nas escolas $13 \%$ e no trabalho $3 \%$, e ainda $19 \%$ dos alunos possuem acesso somente no curso de inclusão digital. 


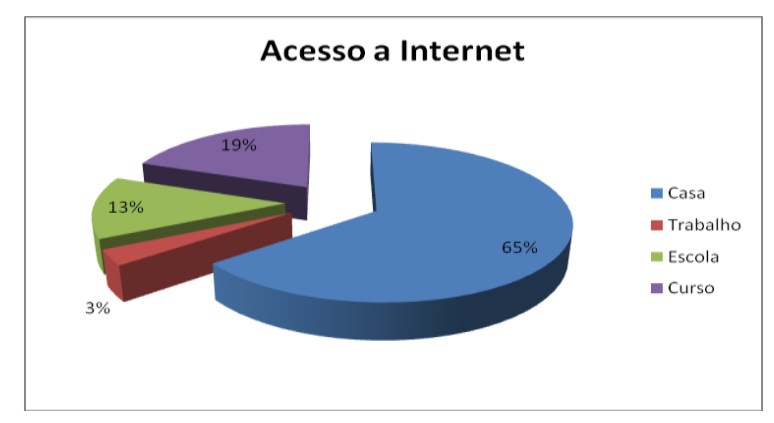

Figura 3. Acesso a Internet

Quanto ao conteúdo adotado pelo Curso, percebemos que a maioria das respostas considera as noções básicas de informática (52\%) de maior relevância, este dado mostra que ainda a grande maioria das pessoas não possui o conhecimento básico do uso do computador. Os demais consideram o uso da internet (48\%) como de maior relevância.

O questionário contava como uma questão aberta que perguntava o seguinte: qual motivo levou você a se inscrever no curso? Percebemos na maioria das respostas como principal motivo à busca pela atualização. Abaixo estão descritos alguns desses comentários:

\footnotetext{
- "Para aprender, porque eu não sei, estou aqui para me atualizar para nós não ficar para traz".

- "Para me atualizar, porque eu preciso saber mais".

- "Porque eu não sei lidar bem com informática, para conhecer um pouco mais e ajudar meu filho na escola".
}

Para SÁ (1999), a atualização é o movimento de acompanhar o momento presente, de inserir-se na dinâmica atual, de sentir-se incluído, envolvido no processo de desenvolvimento da sociedade e conectado ao mundo moderno, associado a informação e comunicação inclusão dentro do convívio com as outras pessoas.

Vendo a tecnologia instalando-se cada vez mais no processo de vida das pessoas, a decisão é enfrentar, pois a alternativa é adentrar esse mundo ou ficar excluído. Acompanhar a evolução tecnológica e os progressos na comunicação, para diminuir o isolamento, sentir-se parte integrante deste novo mundo [Sá, 1999].

Outra percepção que fica claro é a necessidade de se adequarem para o mercado de trabalho, conforme podemos observar em respostas:

- "Temos uma oficina de motos, temos computador, não temos acesso na internet por não saber usar. Faz falta entender e saber".

- "Pela necessidade de aprender para usar no trabalho".

Para Gomes (2002), é extremamente necessário promover a alfabetização digital, ou seja, que capacite as pessoas a utilizar as diversas mídias de acordo com as suas necessidades, considerando que o capital intelectual é cada vez mais imprescindível para que o cidadão se coloque no mercado de trabalho.

\section{Conclusão}

A pesquisa realizada junto ao projeto de extensão em inclusão digital do IFSULCampus Venâncio Aires, mostrou que a exclusão digital perpassa por vários fatores, não 
só pela baixa escolaridade e a maior faixa etária, mas pelo medo de mexer no computador, a falta de oportunidade e conhecimento.

A proposta do curso de inclusão digital deve-se muito a vontade dos alunos, não se sentirem isolados virtualmente, como eles mesmos dizem "não ficar para traz" e se excluírem em um tempo que a tecnologia veio derrubar barreiras e estreitar as distâncias com um simples click do mouse.

Nos dados da pesquisa pudemos perceber que muitos buscam aprimorar seus conhecimentos e dominar a tecnologia "o computador", pois querem uma melhor qualificação através das ferramentas de desenvolvimento pessoal, para assim estarem melhores colocados no mercado de trabalho, dando melhores condições as suas famílias. Já outros não têm a mesma pretensão, suas vontades são de se tornarem ativos no mundo virtual, falarem a mesma língua da maioria, usarem a internet como meio de comunicação, através de e-mail e redes sociais.

Os dados desta pesquisa irão contribuir no aperfeiçoamento do projeto de extensão em inclusão digital. Com estes dados, será possível propor um modelo de curso diferenciado, sendo que este poderá ser pensado de acordo com o perfil oriundos desta pesquisa.

Cabe ressaltar que há muito ainda a ser feito, instituições públicas e privadas e voluntários, precisam atuar juntos no desenvolvimento de projetos que visem a inclusão digital do indivíduo, fornecendo o conhecimento e fazendo com que este sirva para a mudança de seu quadro social.

\section{Referências}

CETIC - Centro de Estudos sobre as Tecnologias da Informação e da Comunicação. Disponível em: http://www.cetic.br. Acesso em: julho de 2013.

GOMES, Elisabeth. Exclusão Digital: um problema tecnológico ou social. Rio de Janeiro: trabalho e sociedade, 2002. Disponível em: http://www.academia.edu/559577/Exclusao_digital_um_problema_tecnologico_ou_s ocial.

IBGE - Instituto Brasileiro de Geografia e Estatística. Disponível em: http://www.ibge.gov.br/. Acesso em: julho de 2013.

MELLO, E F. F.; TEIXEIRA, A. C. Um processo de inclusão digital na hipermodernidade. Simpósio Brasileiro de Informática na Educação, XVIII, 2007, São Paulo. Anais 2007. V.i. P. 58-69.

SÁ, M. A. O idoso e o computador: condições facilitadoras e dificultadoras para o aprendizado. Dissertação de Mestrado em Educação: Psicologia da Educação, PUC/SP, 1999.

SANTOS, M E. A. S. Inclusão Digital: Navegando pelo conhecimento. Trabalho de Conclusão de Curso de Especialização em Educação Profissional e Tecnológica, Cuiabá, 2009. 